Jurnal Keperawatan Silampari

Volume 2, Nomor 1, Desember 2018

e-ISSN : 2581-1975

p-ISSN : 2597-7482

DOI: https://doi.org/10.31539/jks.v2i1.303

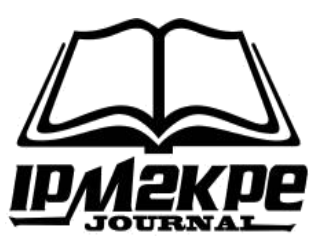

\title{
EFEKTIFITAS RELAKSASI BENSON TERHADAP PENURUNAN NYERI PASIEN PASCA SECTIO CAESAREA
}

\author{
Afnijar Wahyu \\ Program Studi DIII Keperawatan, STIKES Hang Tuah Tanjung Pinang \\ wafniwahyu@gmail.com
}

\begin{abstract}
ABSTRAK
Tujuan penelitian ini adalah untuk mengetahui hubungan pengaruh relaksasi benson terhadap penurunan rasa nyaman nyeri pasien pasca op section caesarea. Metode penelitian ini menggunakan metode kuantitatif dengan desain Quasi eksperimen One group Pre Test dan Post Tes dengan jumlah sampel 22 orang. Hasil penelitian menggunakan analisis Wilcoxon menunjukkan p Value $0.000 \mathrm{p} \leq 0.05$. Simpulan dari penelitian ini ada pengaruh relaksasi benson terhadap penurunan rasa nyaman nyeri pasien pasca op sectio caesarea di RSUD Raja Ahmad Thabib.
\end{abstract}

Kata Kunci: Relaksasi Benson, Sectio Caesarea

\begin{abstract}
The purpose of this study was to determine the relationship of the effect of Benson's relaxation on the reduction of the patient's pain in post-Caesarean section pain. This research method uses a quantitative method with a Quasi experimental design of One group Pre Test and Post Test with a sample of 22 people. The results of the study using Wilcoxon analysis showed $p$ Value 0,000 $p \leq 0.05$. The conclusion of this study is the effect of Benson's relaxation on the reduction of the pain of post-sectio caesarean pain in patients at Raja Ahmad Thabib Regional Hospital.
\end{abstract}

Keywords: Benson Relaxation, Caesarean Sectio 


\section{PENDAHULUAN}

Tindakan pembedahan sering disebut dengan operasi. Operasi merupakan salah satu layanan yang ada di Rumah Sakit. Salah satu tindakan operasi yang dilakukan di Rumah Sakit adalah operasi section caesarea. Menurut (Pohan, 2007) operasi section caesarea merupakan operasi yang paling umum dialami oleh ibu yang akan melahirkan. Jumlah operasi section caesarea mencapai 50\% dari seluruh persalinan di Rumah Sakit (Melisa, 2012).

Sectio caesarea adalah suatu pembedahan guna melahirkan anak lewat insisi pada dinding abdomen dan uterus. Proses kehamilan, persalinan, dan nifas tidak senantiasa berlangsung secara fisiologi namun dapat pula secara patologi. Oleh karena itu pengawasan yang teliti dan terus menerus selama berlangsungnya ketiga proses itu harus dilakukan dengan seksama. Pengawasan bertujuan menemukan sedini mungkin kelainan yang dapat mempengaruhi proses-proses tersebut, agar mendapatkan penanganan yang sebaik-baiknya (Sjamsuhidajat, 2010).

Sectio caesarea adalah pengeluaran janin melalui insisi abdomen. Teknik ini digunakan jika kondisi ibu menimbulkan distres pada janin atau jika telah terjadi distres janin. Sebagai kelainan yang sering memicu tindakan ini adalah malposisi janin, plasenta previa, diabetes ibu, dan disproporsi sefalopelvis janin dan ibu. Sectio caesarea dapat merupakan prosedur elektif atau darurat (Datak, G, 2008).

Sectio caesarea adalah salah satu bentuk pengeluaran fetus melalui sebuah irisan pembedahan yang menembus abdomen seorang ibu (laparotomy) dan uterus (hiskotomy) untuk mengeluarkan satu bayi atau lebih. Sectio caesarea adalah suatu tindakan untuk melahirkan bayi dengan berat diatas 5000 gram, melalui sayatan pada dinding uterus yang masih utuh (Guyton, 2010).

Untuk sectio caesarea biasanya dilakukan anestesi spinal atau epidural. Apabila dipilih anestesi umum, maka persiapan dan pemasangan duk dilakukan sebelum induksi untuk mengurangi efek depresif obat anestesi pada bayi (Gruendemann, 2006). Indonesia, section caesarea hanya dilakukan atas dasar indikasi medis tertentu dan kehamilan dengan komplikasi. Hasil Riskesdas (2013) menunjukkan kelahiran, dengan bedah sectio caesarea sebesar 9,8\% dari total kelahiran, dengan proporsi tertinggi di DKI Jakarta yaitu 19,9\% (Depkes, 2013). Pada pasien pasca operasi section caesarea akan terdapat bekas luka pembedahan dan luka pembedahan tersebut akan menimbulkan rasa nyeri, nyeri pasca operasi section caesarea merupakan hal yang wajar ketika efek pembiusan telah habis, dengan demikian nyeri sangat membuat pasien tidak nyaman, cemas dan rasa takut untuk mobilisasi (Potter, Perry, 2009). Post op sectio caesarea akan menimbulkan nyeri hebat dan proses pemulihannya berlangsung lebih lama di bandingkan dengan persalinan normal (David T, 2007). Pernyataan ini didukung oleh Hestiantoro (2009) persalinan sectio caesarea memiliki nyeri lebih tinggi yaitu sekitar $27,3 \%$ dibandingkan dengan persalinan normal yang hanya sekitar $9 \%$.

Nyeri adalah sensasi yang tidak menyenangkan dan sangat individual yang tidak dapat dibagi kepada orang lain. Nyeri dapat memenuhi seluruh pikiran seseorang, mengatur aktivitasnya, dan mengubah kehidupan orang tersebut (Berman, Kozier 2009). Stimulus nyeri dapat berupa stimulus yang bersifat fisik atau mental, sedangkan kerusakan dapat terjadi pada jaringan aktual atau pada fungsi ego individu (Potter, Perry 2009).

Nyeri dapat diatasi dengan penatalaksanaan nyeri yang bertujuan untuk meringankan atau mengurangi rasa nyeri sampai tingkat kenyamanan yang dirasakan oleh klien. Ada dua cara penatalaksanaan nyeri yaitu farmakologis dan non- 
farmakologis (Smeltzer, Bare 2008). Secara farmakologis dapat diatasi dengan mengunakan obat-obatan analgesik misalnya, morphine sublimaze, stadol, demerol dan lain-lain (Tamsuri, 2012). Kelebihan dari penanganan farmakologis ini adalah rasa nyeri dapat diatasi dengan cepat namun pemberian obat-obat kimia dalam jangka waktu lama dapat menimbulkan efek samping yang dapat membahayakan pemakainnya seperti gangguan pada ginjal (Yosep, 2007). Ada beberapa teknik non farmakologis yang dapat diterapkan dalam mengatasi nyeri yaitu teknik relaksasi benson, akupuntur, transcutanesus electrik nerve stimulations (TENS), Kompres dengan suhu dingin panas, sentuhan pijatan dan hipnotis (Gondo, 2011).

Metode penatalaksanaan nyeri dapat dikelompokkan menjadi katagori yaitu farmakologi dan nonfarmakologi (Andramoyo, 2013). Metode pendekatan farmakologi lebih mahal, dan berpotensi mempunyai efek yang kurang baik. Sedangkan metode non farmakologi lebih murah, simple dan tanpa efek yang merugikan, (Prawirohardjo, S, 2008). Distraksi, relaksasi benson, dan imajinasi terbimbing merupakan beberapa teknik non farmakologi untuk mengurangi nyeri. Penatalaksanaan farmakologi, penggunaan metode farmakologi untuk mengendalikan nyeri membutuhkan perhatian terhadap enam benar yaitu benar obat, benar dosis, benar jalur, benar pasien dan benar pendokumentasian. Selain itu observasi terhadap efek samping obat merupakan tindakan keperawatan yang sangat penting (Hockenberry, Wilson, 2009), analgesik nonnarkotik dan obat anti inflamasi nonsteroid (NSAID), analgesik narkotik atau opiat, Obat tambahan (Adjuvan) (Manuba, Ida Bagus Gede, 2007).

Penatalaksanaan non farmakologis, ada sejumlah terapi non farmakologi yang di gunakan untuk mengurangi nyeri resepsi dan persepsi nyeri, dan dapat di gunakan pada keadaan akut. Tindakan nonfarmakologis mencangkup intervensi perilaku koknitif adalah mengubah persepsi klien tentang nyeri, mengubah prilaku nyeri, dan memberi klien rasa pengendalian yang lebih besar (Potter, Perry, 2006), relaksasi adalah suatu tindakan untuk membebaskan mental dan fisik dari ketegangan dan stres sehingga dapat meningkatkan toleransi terhadap nyeri. Teknik relaksasi yang sederhana terdiri atas napas abdomen dengan frekuensi lambat, berirama. Pasien dapat memejamkan matanya dan bernapas dengan perlahan dan nyaman. Irama yang konstan dapat dipertahankan dengan menghitung dalam hati dan lambat bersama setiap inhalasi ("hirup, dua, tiga") dan (Nugroho, T, 2010).

Distraksi adalah memfokuskan perhatian pasien pada sesuatu selain nyeri, atau dapat di artikan lain bahwa distraksi suatu tindakan pengalihan perhatian pasien ke halhal di luar nyeri. Dengan demikian,di harapankan pasien tidak terfokus pada nyeri lagi dan dapan menurunkan kewaspadaan pasien terhadap nyeri bahkan meningkatkan toleransi terhadap nyeri. Distraksi diduga dapat menurunkan persepsi nyeri dengan menstimulasi sistem kontrol desenden, yang mengakibatkan lebih sedikit stimuli nyeri yang di transmisikan ke otak. Keefektifan distraksasi tergantung pada kemampuan pasien untuk menerima dan membangkitkan input sensori selain nyeri (Mutaqin, 2008). Teknik ini biasanya tidak efektif di berikan kepada pasien yang mengalami nyeri berat atau nyeri akut. Hal ini di sebebkan pada nyeri berat atau akut, pasien tidak dapat berkonsentrasi dengan baik dan tidak cukup baik untuk ikut serta dalam aktifitas mental dan fisik yang kompleks. Imajinasi terbimbing adalah menggunakan imajinasi seseorang dalam suatu cara yang di rancang secara khusus untuk mencapai efek positif tertentu. Tindakan ini membutuhkan konsentrasi yang cukup (Potter, Perry,2005). 
Upaya kondisi lingkungan klien mendukung untuk tindakan ini. Kegaduhan, kebisingan, bau menyengat, atau cahaya yang sangat terang perlu dipertimbangkan agar tidak mengganggu klien untuk berkonstrasi. Beberapa klien lebih rileks dengan cara menutup matanya. Berikut ini merupakan contoh bagai mana melakukan latihan imajinasi terbimbing kepada klien yang mengalami nyeri dengan menggambungkan nafas berirama lambat dengan suatu bayangan mental relaksasi dan kenyamanan, "Bayangkan bahwa setiap desah nafas yang anda hirup saat ini adalah energi penyembuh yang sedang mengalir pelan melalui urat nadi kebagian sakit yang anda sedang alami. Lalu, bayangkan setiap hembusan nafas yang anda keluarkan telah membawa pergi jauh rasa sakit atau nyeri yang anda rasakan ". Lakukan kegiatan ini secara berulang dan teratur dalam beberapa menit (10-15 menit) untuk mendapat kan hasil yang maksimal (Novitasari, Aryana, 2013).

Salah satu upaya nonfarmakologis untuk mengatasi nyeri adalah teknik relaksasi. Teknik relaksasi terbagi atas 4 macam yaitu relaksasi otot (progresive muscle relaxation), pernapasan (diaphragmatic breathing), meditasi (attention focusing exercise) dan relaksasi perilaku (behavioral relaxation) (Miltenbarger, 2004). Kelebihan latihan teknik relaksasi dibandingkan dengan teknik lain adalah teknik relaksasi lebih mudah dilakukan bahkan dalam kondisi apapun serta tidak memiliki efek samping apapun (Novitasari, Aryana, 2013).

Relaksasi Benson merupakan pengembangan metode respon relaksasi pernafasan dengan melibatkan faktor keyakinan pasien yang dapat menciptakan suatu lingkungan internal sehingga dapat membantu pasien mencapai kondisi kesehatan dan kesejahteraan lebih tinggi (Benson, Proctor, 2011).

Prosedur relaksasi benson meliputi langkah-langkah respon relaksasi ini dapat dilakukan sebagai berikut, pilihlah kalimat spiritual yang akan digunakan, duduklah dengan santai, tutup mata, kendurkan otot-otot, bernafaslah secara alamiah (Ralph C, Benson, 2008). Mulai mengucapkan kalimat spiritual yang dibaca secara berulang-ulang khidmat, bila ada pikiran yang mengganggu, kembalilah fokuskan pikiran, lakukan 10 sampai 20 menit, untuk berhenti jangan langsung, duduklah dulu dan beristirahat. Buka pikiran kembali. Barulah berdiri dan melakukan kegiatan kembali. Menurut Benson, yang menemukan tehnik ini, cara ini bisa diubah misalnya tidak dengan posisi duduk tapi dilakukan sambil melaksanakan gerakan jasmani. Respon relaksasi dengan melibatkan faktor keyakinan pasien, yang dapat menciptakan suatu lingkungan internal sehingga dapat membantu pasien mencapai kondisi kesehatan dan kesehjahteraan lebih tinggi (Sanjaya, J, 2015).

Kebutuhan pelayanan kesehatan sebagai suatu kebutuhan akan kenyamanan, yang dihasilkan dari situasi pelayanan kesehatan yang stressful, yang tidak dapat dipenuhi oleh penerima support sistem tradisonal. Kebutuhan ini meliputi kebutuhan fisik, psikospiritual, social dan lingkungan, yang kesemuanya membutuhkan monitoring. Relaksasi benson ini sudah dilakukan dibeberapa penelitian eksperimen. Menurut penelitian yang telah dilakukan Novitasari, Aryana (2013) yang berjudul pengaruh relaksasi benson terhadap penurunan tingkat stress lansia.

Menurut data Dinas Kesehatan Kota Tanjungpinang, didapatkan angka kejadian pasien dengan sectio caesarea pada bulan April 2014 yaitu sebanyak 65 ibu dan mengalami peningkatan drastis April 2015 dengan angka kejadian 574 ibu dilakukan operasi sectio caesarea. Dari data yang didapat di RSUD Raja Ahmad Tabib angka kejadian sectio caesarea pada tahun 2017 dari bulan Januari sampai November ada 220 pasien menjalankan sectio caesarea dan didapatkan juga angka kejadian di Rumkital 
Dr. Midiyanto Suratani pada tahun 2017 dari bulan Januari sampai Desember ada pasien 156 pasien. Dapat disimpulkan bahwa angka prevalensi pada penderita yang dilakukan operasi sectio caesarea terbanyak adalah RSUD Raja Ahmad Tabib.

Tujuan umum penelitian ini adalah untuk mengetahui pengaruh terapi relaksasi benson terhadap penurunan nyeri pasien pascasectio caesarea di RSUD Ahmad Thabib Tahun 2018. Diketahuinya distribusi karakteristik (usia, pendidikan dan suku) pasien dengan skala nyeri pada pasien pascasectio caesarea sebelum dilakukan relaksasi Benson, diketahuinya distribusi skala nyeri pada pasien pasca sectio caesarea sesudah dilakukan relaksasi benson, diketahuinya seberapa besar pengaruh relaksasi benson terhadap penurunan skala nyeri pada pasca sectio caesarea.

\section{METODE PENELITIAN}

Penelitian ini menggunakan desain penelitian eksperimen semu (Quasi eksperimen) yaitu penelitian yang menguji coba suatu intervensi pada kelompok subjek dengan atau tanpa kelompok pembanding namun tidak dilakukan randomisasi untuk memasukkan subjek kedalam kelompok eksperimen perlakuan atau control. Penelitian ini menggunakan rancangan One Group Pre Test dan Post test. Penelitian ini dilakukan dengan cara pengamatan pertama (Pre test) terlebih dahulu sebelum diberikan intervensi perlakuan, setelah itu diberikan intervensi kemudian dilakukan pengamatan akhir (Post test).

Pre test Perlakuan Post test

\begin{tabular}{|lll|}
\hline 01 & $\mathrm{X}$ & 02 \\
\hline
\end{tabular}

Keterangan:

Gambar. 1 Rancangan Penelitian (Notoatmojo, 2010)

01 : Nyeri sebelum dilakukan relaksasi benson

$\mathrm{X} \quad$ : Dilakukan intervensi relaksasi benson

02 : Nyeri sesudah dilakukan relaksasi benson

\section{Populasi dan Sampel}

Populasi penelitian merupakan keseluruhan objek yang di teliti tersebut (Notoadmodjo, 2010). Pendapat lain menyatakan bahwa populasi adalah keseluruhan jumlah subjek yang mempunyai karakteristik dan kualitas tertentu yang ditetapkan oleh peneliti untuk diteliti dan kemudian ditarik kesimpulannya (Wiratna, 2014). Populasi pada penelitian ini yaitu klien dengan nyeri pasca secsio caesarea di RSUD Raja Ahmad Thabib tahun 2017 dengan jumlah 220 orang.

Sampel terdiri atas bagian populasi terjangkau yang dapat dipergunakan sebagai subjek penelitian melalui teknik sampling. Sedangkan teknik sampling adalah proses menyeleksi porsi dari populasi yang dapat mewakili populasi yang ada (Nursalam, 2013). Pengambilan sampel dalam penelitian ini diambil menurut (Arikunto, 2010) yang menyatakan jika subjeknya kurang dari 100 orang sebaiknya diambil semuanya, jika subjeknya besar atau lebih dari 100 orang, dapat diambil $10-15 \%$ atau $20-25 \%$ atau lebih sehingga sampel dalam penelitian ini adalah:

Kriteria inklusi dalam penelitian ini sebagai berikut, Klien dengan nyeri pasca sectio caesarea di RSUD Raja Ahmad Thabib, klien dengan nyeri pasca sectio caesarea yang mampu memahami pertanyaan dan bersedia mengikuti prosedur, klien dengan pasca nyeri pasca sectio caesarea dengan tingkat nyeri ringan- sedang berada diwilayah 
kota Tanjungpinang klien dengan 2 hari pasca sectio cesarean, klien yang bersedia menjadi responden. Adapun kriteria eksklusi pada penelitian ini adalah klien yang mengalami nyeri pasca sectio caesarea dengan skala berat, klien yang mengalami nyeri pasca sectio caesarea yang tidak mampu memahami dan tidak bersedia mengikuti prosedur.

\section{Teknik Pengumpulan Data}

Pengumpulan data merupakan langkah yang sangat penting dalam penelitian, karena data yang terkumpul digunakan untuk menguji hipotesis yang telah dirumuskan (Notoatmodjo, 2010). Dalam mengumpulkan data pada penelitian, peneliti menggunakan lembar observasi. Setelah pengumpulan data dilakukan, tahap selanjutnya akan dilakukan pengolahan data dengan proses komputerisasi, langkah-langkah proses pengolahan data sebagai berikut: 1) Editing (proses penyuntingan), Editing adalah upaya untuk memeriksa kembali kebenaran data yang diperoleh atau dikumpulkan. Secara umum editing dilakukan untuk mengecek, atau perbaikan isi lembar observasi atau penulisan hasil pengukuran skala nyeri, 2) Coding (pengkodean data), Coding yaitu melakukan pemberian kode (angka) terhadap data yang terdiri atas beberapa katagori. Pemberian kode data ini sangat penting bila pengolahan data dan analisis data menggunakan computer, 3) Entry data (memasukkan data), Proses memasukan data dari hasil obeservasi dari responden akan diolah melalui komputer pada program statistiaka. pengolah data agar dianalisis. Data yang telah di entri dengan menggunakan komputer, setelah semua data observasi terpenuhi dan benar, dan sudah melewati proses pengkodingan dan tabulasi, maka langkah selanjutnya peneliti akan memperoses data agar dapat dianalisis, 4) Scoring data yang diolah telah dimasukkan dan diberikan penilaian skor masing-masing sehingga data tersebut dapat dianalisis, 5) Cleaning Cleaning merupakan kegiatan pemeriksaan kembali data yang sudah dimasukkan, apakah ada kesalahan atau tidak. Apabila semua data dari setiap sumber data atau responden selesai maka data-data tersebut siap untuk dianalisi, 6) Teknik analisa data, Analisa data bertujuan untuk menjelaskan tentang metode statistika yang digunakan dalam menganalisis data hasil penelitian (Hidayat, 2009).

\section{Waktu Penelitian}

Penelitian yang dilakukan ini dibagi menjadi tiga tahapan waktu, yakni persiapan, pelaksanaan dan penyusunan laporan. Tahap persiapan dimulai pada tanggal 16 Oktober 2017 sampai dengan tanggal 24 November 2017. Pada tahap persiapan ini peneliti melakukan studi pendahuluan dan studi kepustakaan hingga dilanjutkan dengan penyusunan proposal, sidang proposal, dan revisi proposal hingga diizinkan untuk melakukan penelitian. Tahap pelaksanaan untuk pengumpulan data di mulai pada tanggal 27 Februari 2018 sampai dengan tanggal 27 Maret 2018. Tahapan selanjutnya yaitu pengolahan data dan penyusunan laporan penelitian yang dimulai tanggal 28 Maret 2018 sampai tanggal 20 April 2018.

\section{Analisa Penelitian}

Analisa data dalam penelitian terdiri dari analisis univariat dan analisis bivariat (Notoatmodjo, 2010) yaitu 1) Uji Univariat, Analisis univariat bertujuan untuk menjelaskan atau mendeskripsikan karakteristik setiap variabel penelitian (Notoatmodjo, 2010). Pada umumnya dalam analisis ini hanya menghasilkan distribusi frekuensi dan persentase dari setiap variabel (Notoatmodjo, 2010). Pada penelitian ini 
analisis univariat dilakukan untuk mendeskripsikan variabel skala nyeri sebelum dan sesudah diberikan perlakuan relaksasi benson di RSUD Raja Ahmad Tabib 2018, 2) uji bivariat, analisa bivariat adalah analisa yang dilakukan terhadap dua variabel yang diduga berhubungan atau berkolerasi (Notoatmodjo, 2010). Analisa bivariat pada penelitian ini menggunakan uji statistik non parametrik yaitu test uji Wilcoxon dimana bertujuan untuk mengetahui perbedaan antara data yang berpasangan, menguji komparasi antara 2 pengamatan sebelum dan sesudah dan mengetahui efektifitas suatu perlakuan.

\section{Alat Pengumpulan Data}

Alat pengumpulan data yang dilakukan antara lain membuat surat izin penelitian dari institusi pendidikan untuk diserahkan ketempat penelitian, meminta izin untuk melakukan penelitian di wilayah yang sudah dipilih, membuat jadwal penelitian, memilih responden sesuai kriteria inklusi, menjelaskan prosedur penelitian, memberikan lembar persetujuan (informed consent) kepada responden, melakukan pre test pada penderita dengan perkiraan waktu 10 menit, melakukan pemberian perlakuan yaitu relaksasi benson pada pasien pasca op sectio caesarea serta melakukan post test setelah perlakuan dengan perkiraan waktu 10 menit.

\section{HASIL PENELITIAN}

Analisa Univariat

Tabel. 1

Karakteristik Responden

\begin{tabular}{ccc}
\hline Variabel & $\mathrm{N}$ & $\%$ \\
\hline Katagori umur: & & \\
25-30 Tahun & 11 & 50 \\
31-34 Tahun & 11 & 50 \\
\hline Tingkat pendidikan: & & \\
SD & 3 & 13,7 \\
SMP & 3 & 13,7 \\
SMA & 10 & 45 \\
S1 & 6 & 27,2 \\
\hline
\end{tabular}

Deskripsi data hasil penelitian ini adalah tentang pengaruh pemberian relaksasi benson terhadap penurunan nyeri pasien pasca sectio caesarea di Rumah Sakit Umum Daerah Raja Ahmad Thabib. Dengan jumlah responden sebanyak 22 responden.

Deskripsi data dari hasil penelitian ini menggunakan analisis univariat bertujuan untuk mendiskripsikan karakteristik usia, pendidikan. Analisis bivariat bertujuan untuk melihat pengaruh relaksasi benson terhadap rasa nyaman nyeri. Penelitian ini menggunakan uji statistic wilcoxon test. Deskripsi data dalam penelitian ini disajikan dalam bentuk tabel.

Berdasarkan tabel 1 diketahui bahwa dari 22 orang responden, distribusi responden usis 25-30 tahun dengan jumlah 11 orang responden $(50 \%)$, sedangkan menurut pendidikan terahir yang terbanyak pendidikan menengah atas serjumlah 10 orang responden $(45 \%)$. 
Tabel. 2

Distribusi Rata-Rata Nyeri Section Caesarea saat Pre-Test

\begin{tabular}{ccc}
\hline Keterangan nyeri & $\mathrm{N}$ & $\%$ \\
\hline Nyeri Berat & 0 & 0 \\
Nyeri Sedang & 18 & 82 \\
Nyeri Ringan & 4 & 18 \\
Tidak Nyeri & 0 & 0 \\
\hline
\end{tabular}

Berdasarkan tabel 2 dapat diketahui skala nyeri dari 22 responden sebelum diberikan relaksasi benson sebagian besar responden memiliki skala nyeri sedang sebanyak 18 (82), dan nyeri ringan 4 (18) responden.

Tabel. 3

Distribusi Rata-Rata Nyeri Section Caesarea saat Post-Test

\begin{tabular}{lcc}
\hline Keterangan nyeri & $\mathrm{N}$ & $\%$ \\
\hline Nyeri Berat & 0 & 0 \\
Nyeri Sedang & 4 & 18 \\
Nyeri Ringan & 18 & 82 \\
Tidak Nyeri & 0 & 0 \\
\hline
\end{tabular}

Berdasarkan tabel 3 dapat diketahui skala nyeri dari 22 responden sebelum diberikan relaksasi benson sebagian besar responden memiliki skala nyeri sedang sebanyak 4 (18), dan nyeri ringan 18 ( 82 ) responden.

\section{Analisa Bivariat}

Tabel. 4

Perbedaan Rata-Rata Nyeri pada Pasien Pasca Section Caesarea Sebelum dan Sesudah Diberikan Relaksasi Benson

\begin{tabular}{cccccc}
\hline Variabel & Mean & SD & Min & Max & P Value \\
\hline Skala nyeri pre & 4,55 & 1.057 & 3 & 6 & 0,000 \\
\hline Skala nyeri post & 3,00 & 7.33 & 2 & 4 & \\
\hline
\end{tabular}

Berdasarkan tabel 4 dapat dilihat bahwa hasil analisi menunjukkan median skala nyeri sebelum dilakukan relaksasi benson adalah 4,55. Nilai skala nyeri sebelum dilakukan terapi benson minimum adalah 3 maksimum 6. Dapat dilihat bahwa hasil analisa menunjukkan median skala nyeri sesudah dilakukan relaksasi benson adalah 3,00. Nilai skala nyeri sebelum dilakukan relaksasi benson minimum adalah 2 maksimum.

\section{Pengujian Persyaratan Analisis}

Setelah didapatkan data dari hasil penelitian maka akan dioleh menggunakan statistika. Dan terlebih dahulu data akan diuji menggunakan uji normalitas data untuk mengetahui bagaimana distribusi penyebaran data dan untuk mengetahui uji apa yang cocok untuk digunakan mengolah data hasil penelitian. Dalam penelitian ini distribusi data rasa nyaman nyeri pretest maupun posttest tidak terdistribusi secara normal dengan hasil nilai uji shapiro-wilk sebesar 0,001 selain itu skala yang digunakan dalam penelitian ini adalah numerik dengan data yang berpasangan sehingga analisis statistik yang akan digunakan adalah uji nonparametric wilcoxon. 


\section{PEMBAHASAN}

\section{Karakteristik Responden}

Berdasarkan hasil penelitian yang telah dilakukan pada pasien nyeri pasca sectio caesarea di RSUD Raja Ahmad Thabib didaptkan bahwa responden yang berusis 25-30 tahun sebanyak 11 orang (50\%) dan pada usia 31-34 tahun sebanyak 11 orang (50\%). Rentang umur 20-34 tahun merupakan rentang umur wanita subur. Menurut (Hestiantaro, 2009) salah satu faktor yang mempengaruhi respon nyeri adalah usia, usia merupakan variabel yang penting yang mempengaruhi nyeri. Perbedaan perkembangan yang ditemukan diantara kedua kelompok usia dapat mempengaruhi cara bereaksi terhadap nyeri.

Anak yang masih kecil mempunyai kesulitan memahami nyeri dan prosedur yang dilakukan perawat yang menyebabkan nyeri. Anak-anak kecil yang belum dapat mengucapkan kata-kata juga mengalami kesulitan untuk mengungkapkannya secara verbal dan mengekspresikan nyeri kepada orang tua atau petugas kesehatan. Pada sebagian anak terkadang segan untuk mengungkapkan keberadaan nyeri yang ia alami, disebabkan mereka takut akan tindakan perawatan yang harus mereka terima nantinya.

Pada pasien lansia, seorang perawat harus melakukan pengkajian lebih rinci ketika seorang lansia melaporkan adanya nyeri. Sering lansia memiliki sumber nyeri yang lebih dari satu. Terkadang penyakit yang berbeda-beda yang diderita lansia menimbulkan gejala yang sama, sebagai contoh nyeri dada dapat timbul karena gejala arthritis pada spinal dan gejala pada gangguan abdomen. Sebagian lansia terkadang pasrah terhadap apa yang mereka rasakan, mereka menganggap bahwa hal tersebut merupakan konsekuensi penuaan yang tidak bisa dihindari.

Meskipun banyak lansia mencari perawatan kesehatan karena nyeri, lansia yang lainnya enggan untuk mencari bantuan, bahkan ketika mengalami nyeri hebat, karena mereka menganggap bahwa nyeri yang dirasakan adalah bagian dari proses penuaan yang normal yang terjadi pada setiap lansia. Diperkirakan lebih dari 85\% dewasa tua mempunyai sedikitnya satu masalah kesehatan kronis yang dapat menyebabkan nyeri. Lansia cenderung untuk mengabaikan nyeri dan menahan nyeri yang berat dalam waktu yang lama sebelum melaporkannya atau mencari perawatan kesehatan. Sementara sebagian yang lainnya tidak mencari perawatan, karena merasa takut nyeri tersebut menandakan penyakit yang serius atau mereka takut kehilangan kontor.

Responden berasal dari berbagai suku yaitu Melayu, Batak, Boyan, Jawa, Minang dan Bugis dengan suku terbanyak adalah jawa sebanyak 10 orang (46\%). Sampai saat ini belum dinyatakan bahwa kejadian section caesarea lebih banyak pada suku tertentu, sehingga karakteristik tersebut tidak berperan dalam kejadian pasien yang mengalami sectio caesarea, namun sesuai dengan penelitian Syahriyani (2010) menyatakan bahwa faktor yang mempengaruhi nyeri seseorang diantaran usia, jenis kelamin, dan kebudayaan.

Berdasarkan tingkat pendidikan didapatkan bahwa status pendidikan responden terbanyak adalah SMA yang berjumlah 10 responden (45 \%). Hal ini sesuai dengan hasil penelitian sebelumnya yang dilakukan oleh Patasik, Tangka, Rottie (2013) yang menyatakan bahwa secara umum responden section caesarea berdasarkan tingkat pendidikan SMA yaitu sebanyak 18 responden $(90,0 \%)$. Banyaknya responden setelah lulus SMA lebih disebabkan responden tidak melanjutkan ke perguruan tinggi melainkan memilih untuk menikah.

Keyakinan dan nilai-nilai kebudayaan memengaruhi cara individu mengatasi nyeri. Individu mempelajari apa yang diharapkan dan apa yang diterima oleh 
kebudayaan mereka. Hal ini meliputi bagaimana bereaksi terhadap nyeri (Potter, Perry, 2006). Budaya dan etnisitas berpengaruh pada bagaimana seseorang merespon terhadap nyeri. Sejak dini pada masa kanak-kanak, individu belajar dari sekitar mereka respons nyeri yang bagaimana yang dapat diterima atau tidak diterima.

Tingkat pendidikan mempengaruhi perilaku dan menghasilkan banyak perubahan, khususnya pengetahuan dibidang kesehatan. Semakin tinggi pendidikan seseorang semakin mudah pula menerima informasi dan pada akhirnya makin banyak pula pengetahuan yang dimiliki. Tingkat pendidikan seseorang dalam menerima informasi dan mengolahnya sebelum menjadi prilaku yang baik maupun buruk sehingga berdampak terhadap status kesehatannya (Notoadmojo, 2010).

Hasil pengamatan penelitian yang lebih lanjut terhadap nyeri yang dialami pasien pasca sectio caesarea di RSUD Raja Ahmad Thabib dijumpai hasil analisis. Hasil penelitian yang didapatkan peneliti relaksasi benson saat pretest didapatkan nilai median 4,50 dan masih berada pada nyeri sedang setelah dilakukan post test 3,00. $\mathrm{P}$ value untuk relaksasi benson $0,001<0,05$ maka Ho ditolak artinya ada pengaruh penurunan rasa nyaman nyeri pada pasien pasca section caesarea pada perlakuan relaksasi benson.

Maka dari itu perlakuan relaksasi benson terhadap masing-masing pasien mencapai hasil yang maksimal dengan penuruan rasa nyeri pasca section caesarea yang rendah atau pun ada pengaruh setelah dilakukan perlakuan relaksasi benson. Sebenarnya, persalinan melalui bedah sectio caesarea tidak mempengaruhi persalinan berikutnya harus berlangsung secara operasi atau tidak. Apabila memang ada indikasi yang mengharuskan dilakukannya tindakan bedah, seperti bayi terlalu besar, panggul terlalu sempit atau jalan lahir tidak mau mebuka, partus tak maju, operasi bisa saja dilakukan.

Menurut Anita (2015) relaksasi benson merupakan pengembangan metode respon relaksasi pernafasan dengan melibatkan faktor keyakinan pasien yang dapat menciptakan suatu lingkungan internal sehingga dapat membantu pasien mencapai kondisi kesehatan dan kesejahteraan lebih tinggi (Benson, Proctor, 2000).

Relaksasi benson adalah suatu jenis terapi untuk penanganan kegiatan mental dan menjauhkan tubuh dan pikiran dari rangsangan luar untuk mempersiapkan tercapainya hubungan yang lebih dalam dengan pencipta, yang dapat dicapai dengan metode hypnosis, meditasi yoga, dan bentuk latihan-latihan yang ada hubungannya dengan penjajakan pikiran (Kasdu. 2003). Relaksasi benson merupakan pengembangan metode respon relaksasi dengan melibatkan keyakinan pasien, mendapat menciptakan suatu lingkungan tenang sehingga dapat membantu pasien mencapai kondisi kesehatan dan kesejahteraan lebih tinggi (Purwanto, 2011).

Relaksasi bensom merupakan tehnik relaksasi yang digabungkan dengan keyakinan/keimanan yang dianut oleh pasien. Ungkapan yang dipakai dapat berupa nama tuhan atau kata-kata lain yang dimiliki oleh efek menenangkan bagi pasien yang dibaca secara berulang-ulang (Benson, Proctor, 2011). Relaksasi benson yaitu tehnik pengobatan untuk menghilangkan nyeri, insomnia (tidak bisa tidur).

Cara pengobatan ini merupakan pembagian pengobatan spritual. Pada tehnik ini pengobatan sangat fleksibel dapat dilakukan dengan bimbingan mentor, bersama-sama atau sendiri. Tehnik ini merupakan upaya untuk memusatkan perhatian pada suatu fokus yang menyebut berulang-ulang kalimat ritual dan menghilangkan berbagai pikiran yang mengganggu. Tehnik pengobatan ini dapat dilakukan setengah jam 2 kali sehari (Sanjaya, J. 2015). 
Menurut Purwanto (2011) tujuan dilakukannya relaksasi benson adalah untuk menciptakan suasana intern yang nyaman sehingga mengalirkan fokus terhadap sensasi nyeri pada hipotalamus sehingga dapat menurunkan sensasi nyeri yang dirasakan oleh individu yang bersangkutan.

Mansjoer, dkk (2008) mengatakan bahwa nyeri merupakan suatu mekanisme produksi bagi tubuh, timbul ketika jaringan sedang rusak, dan menyebabkan individu tersebut bereaksi untuk menghilangkan rasa nyeri. Selanjutnya, Judha, M (2012) mengatakan bahwa nyeri adalah pengalaman pribadi, subjektif, yang dipengaruhi oleh budaya, persepsi seseorang, perhatian dan variabel-variabel psikologis lain, yang mengganggu prilaku berkelanjutan dan memotivasi setiap orang untuk menghentikan rasa tersebut.

Judha, M (2012) menyatakan nyeri didefinisikan sebagai pengalaman yang tidak menyenangkan, baik sensori maupun emosional yang berhubungan dengan risiko atau aktualnya kerusakan jaringan tubuh. Prasetyo (2010) menyatakan bahwa hanya klienlah yang paling mengerti dan memahami tentang nyeri yang ia rasakan. Oleh karena itulah dikatakan klien sebagai expert tentang nyeri yang ia rasakan.

Terdapat berbagai faktor yang dapat memengaruhi persepsi individu terhadap nyeri. Sebagai tenaga kesehatan, seorang perawat perlu memahami faktor-faktor tersebut agar dapat memberikan pendekatan yang tepat dalam pengkajian dan perawatan terhadap klien yang mengalami masalah nyeri (Andarmoyo, Suharti, 2015)

Menurut Syahriyani (2010) perbedaan tingkat nyeri yang dipersepsikan oleh pasien disebabkan oleh kemampuan sikap individu dalam merespon dan mempersepsikan nyeri yang dialami. Kemampuan mempersepsikan nyeri dipengaruhi oleh beberapa faktor dan berbeda diantara individu. Tidak semua orang terpajan terhadap stimulasi yang sama mengalami intensitas nyeri yang sama. Sensasi yang sangat nyeri bagi seorang mungkin hampir tidak terasa bagi orang lain.

\section{Gambaran Nyeri Pasca Section Caesarea Sebelum dan Sesudah Menggunakan Relaksasi Benson pada Pasien Pasca Section Caesarea}

Hasil pengamatan penelitian terhadap nyeri pasca section caesarea sebelum dilakukan teknik relaksasi benson, diketahui sebagian besar responden memiliki nyeri sedang sebanyak 18 orang $(81,8 \%)$ dan pada saat post test diketahui sebagian besar memiliki nyeri sedang sebanyak 4 orang $(18,4 \%)$. Secara garis besar terdapat perubahan nyeri pada pasien saat sebelum dan sesudah menggunakan teknik relaksasi benson. Terlihat ada perubahan katagori nyeri yang berarti setelah dilakukan teknik relaksasi benson. Dengan kata lain dengan relaksasi benson dapat mengurangi nyeri pasien pasca section caesarea. Menurut peneliti, yang menyebabkan terjadinya penurunan nyeri setelah melakukan teknik relaksasi benson disebabkan oleh pengalihan fokus nyeri.

Menurut Purwanto (2011) tujuan dilakukannya relaksai benson adalah untuk menciptakan suasana intern yang nyaman sehingga mengalirkan fokus terhadap sensasi nyeri pada hipotalamus sehingga dapat menurunkan sensasi nyeri yang dirasakan oleh individu yang bersangkutan.

Relaksasi benson dalam hal berperan untuk menurunkan intensitas persepsi nyeri bekerja dengan cara mengalihkan fokus seseorang terhadap nyeri dan dengan menciptakan suasana nyaman serta tubuh yang rileks maka tubuh akan meningkatkan proses analgesia endogen hal ini diperkuat dengan adanya kalimat atau mantra yang memiliki efek menenangkan atau menggunakan kata-kata yang mampu mempengaruhi 
korteks serebri karena tehnik relaksasi benson menyatakan unsur religi didalamnya diamana semua umat yang percaya akan "sang pencipta" juga percaya akan "kuasanya" dimana hal ini semakinmemberikan efek relaksasi yang pada akhirnya meningkatkan proses analgesia endogen sehingga mampu menggurangi persepsi nyeri seseorang.

Memindahkan pikiran-pikiran yang berorientasi pada hal-hal yang logis dan yang berada diluar diri harus ada suatu rangsangan yang konstan yaitu satu kata atau frase singkat yang diulang-ulang dalam hati sesuai dengan keyakinan. Kata atau frase yang singkat merupakan fokus dalam melakukan relaksasi benson. Fokus terhadap kata atau frase singkat akan meningkatkan kekuatan dasar respons relaksasi dengan memberi kesempatan faktor keyakinan untuk memberi pengaruh terhadap penurunan aktifitas saraf simpatik (Benson, Proctor, 2009). Salah satu kesulitan untuk dalam pelaksanaan Relaksasi Benson adalah pikiran yang mengembara, namun dapat dicegah dengan pengulangan kata atau frase. Mata biasanya terpejam apabila tengah mengulang kata atau frase singkat. Relaksasi Benson dilakukan 1 sampai 2 kali sehari selama 10-20 menit. Waktu yang baik untuk memperaktekan relaksasi benson adalah sebelum makan atau beberapa jam sesudah makan, karena selama melakukan relaksasi, darah akan dialirkan kekulit, otot-otot ekstremitas, otak dan menjauhi daerah perut sehingga efeknya akan bersaing dengan proses makanan (Benson, Proctor, 2009).

\section{Pengaruh Pemberian Relaksasi Benson terhadap Penurunan Nyeri pada Pasien}

Setelah didapatkan data dari hasil penelitian maka akan dioleh menggunakan statistika. Dan terlebih dahulu data akan diuji menggunakan uji normalitas data untuk mengetahui bagaimana distribusi penyebaran data dan untuk mengetahui uji apa yang cocok untuk digunakan mengolah data hasil penelitian. Dalam penelitian ini distribusi data rasa nyaman nyeri pre test maupun post test tidak terdistribusi secara normal dengan hasil nilai uji shapiro-wilk sebesar 0,001 selain itu skala yang digunakan dalam penelitian ini adalah numerik dengan data yang berpasangan sehingga analisis statistik yang akan digunakan adalah uji non parametric wilcoxon.

Menurut Purwanto (2011) tujuan dilakukannya relaksai benson adalah untuk menciptakan suasana intern yang nyaman sehingga mengalirkan fokus terhadap sensasi nyeri pada hipotalamus sehingga dapat menurunkan sensasi nyeri yang dirasakan oleh individu yang bersangkutan.

Menurut Andarmoyo (2013) menyebutkan pada awal terjadinya nyeri dimulai dengan adanya stimulus nyeri dalam hal ini stimulus mekanik (pasca operasi TURP) yang dihantarkan oleh nociceptor mekanis menuju sistem syaraf pusat lalu stimulus nyeri ini diubah menjadi suatu aktivitas listrik yang akan diterima ujung-ujung syaraf atau proses ini dikenal dengan nama transduksi. Selanjutnya adalah proses transmisi dimana impuls nyeri dari nociceptor akan menuju korteks serebriatau tempat memproses sensori.

\section{Efektifitas Relaksasi Benson terhadap Nyeri Pasca Section Caesarea}

Berdasarkan hasil uji statistika dengan menggunakan uji Wilcoxon didapatkan nilai $\mathrm{p}$ value nyeri 0,000 berarti $\mathrm{p}$ value $<0,05$ maka Ho ditolak, yang berarti bahwa nyeri pada ibu pasca section caesarea dengan menggunakan relaksasi benson lebih efektif untuk menurunkan skor nyeri.

Hasil penelitian ini mendukung penelitian yang dilakukan oleh Puput Nur Fadilah, Puji Astuti, dan Wesiana Heris Santy (2016) yang berjudul pengaruh relaksasi benson terhadap penurunan skala nyeri dada kiri pada pasien acute myocardial infarc di RS Dr 
Moewardi Surakarta Tahun 2014. Hasil uji statistik menunjukkan bahwa p value pada kelompok kontrol sebesar $0,004(\alpha=0,05)$ sehingga dapat disimpulkan bahwa terapi analgetik berpengaruh terhadap penurunan skala nyeri pada respondend dengan AMI.

Sejalan dengan penelitian yang dilakukan penelitian Purwanto (2011) dengan judul pengaruh teknik relaksasi benson terhadap skala nyeri pada pasien post operasi di RSUP. Prof. Dr.R.D. Kandou dan RS Tk.III R.W Mongisi di Teling Manado. Hasil uji statistik wilcoxon sigh rank test dengan tingkat kepercayaan $95 \%(\alpha=0,05)$ dan diperoleh $p$ value $0,000,<0,05$.

Menurut Penelitian Anita Yusliana, Misrawatin \& Safri (2015) yang berjudul efektivitas relaksasi benson terhadap penurunan nyeri pada ibu postpartum sectio caesarea. Hasil uji statistika menggunakan uji $t$ independent. Nilai $\mathrm{p}$ value $(0,000)<\alpha$ $(0,05)$, maka Ho ditolak sehingga dapat disimpulkan bahwa pemberian relaksasi benson efektif terhadap penurunan skor nyeri pada ibu post partum sectio caesarea.

Teknik relaksai nafas dalam ini dapat merangsang tubuh menghasilkan endorphin dan enfikelin ini adalah zat kimiawi endogen yang bersetruktur seperti opioid, yang mana endorphin dan enfikelin dapat menghambat imflus nyeri dengan memblok transmisi implus didalam otak dan medulla spinali.

\section{SIMPULAN}

Berdasarkan hasil penelitian yang dilakukan kepada 22 responden dan hanya menggunakan kelompok eksperimen tanpa kelompok kontrol dengan pemberian relaksasi benson di Rumah Sakit Umum Daerah Raja Ahmad Thabib, maka peneliti menarik kesimpulan diketahui distribusi frekuensi pasien pasca op section caesarea berada pada usia (25-34 tahun) merupakan rentang umur wanita usia subur karena sistem reproduksinya sedang aktif-aktifnya, diketahui distribusi skala nyeri pada pasien pasca section caesare sebelum dan sesudah diberikan relaksasi benson hasil pre test dengan nilai 4-6 (81,8 \%) sedangkan post test dengan nilai 1-3 (81,8\%), pada hasil penelitian menggunakan uji statistik wilcoxon yang menghasilkan nilai $\mathrm{p}$ value $=0,000$, yaitu Ho ditolak, yang artinya ada hubungan pemberian relaksasi benson dengan kejadian rasa nyaman nyeri pasien pasca op section caesarea di RSUD Raja Ahmad Thabib Tahun 2018.

\section{SARAN}

1. Untuk menjaga sikap loyalitas responden yang sudah baik, perlu dilakukan upaya peningkatan kualitas layanan secara terus menerus terutama dalam dimensi responsiveness terhadap pasien yang dinilai memiliki pengaruh paling besar dalam aspek kualitas layanan terhadap loyalitas pasien dalam penelitian ini.

2. Aspek dari kualitas pelayanan keperawatan yang perlu ditingkatkan adalah pemahaman perawat tentang manajemen mutu serta aplikasi dalam manejemen ruangan dalam rangka mengelola pelayanan keperawatan beserta ruang rawat yang berorientasi pada kebutuhan pasien, dengan metode penugasan yang efektif maka kebutuhan pasien akan lebih terpenuhi.

3. Melakukan evaluasi secara berkala mengenai kualitas pelayanan keperawatan dan melakukan sistem keluhan dan saran dengan customer care secara rutin dengan memberikan kesempatan seluas luasnya pada pasien untuk memberikan saran, pendapat dan keluhan. Media yang dapat digunakan meliputi kotak saran dengan menyedikan kartu komentar yang dapat diisi langsung. 
4. Penelitian ini digunakan sebagai dasar penelitian berikutnya dengan menggunakan variabel lain yang berhubungan dengan loyalitas pasien seperti kepuasan pasien, hambatan pindah, citra rumah sakit dan-lain sebagainya. Pengumpulan data dapat lebih dikembangkan dengan menggunakan kuesioner dan wawancara mendalam serta dengan rancangan penelitian yang berbeda agar data atau informasi yang didapatkan dapat lebih akurat dan mendalam.

5. Diharapkan untuk peneliti selanjutnya melakukan analisis terkait klasifikasi nyeri apa yag dapat digunakan dengan terapi benson. 


\section{DAFTAR PUSTAKA}

Afroh, F., Mohamad Judha, Sudarti. (2012). Teori Pengukuran Nyeri \& Nyeri Persalinan. Yogyakarta: Nuha Medika

Andarmayo, S. (2013). Konsep dan Proses Keperwatan Nyeri. Yogyakarta: ArRuzz media

Anita, Y., Misrawati \& Safri. (2015). Efektivitas Relaksasi Benson terhadap Penurunan Nyeri pada Ibu Postpartum Sectio Caesarea. Jurnal Keperawatan Indonesia, 2(2), 944-952. Diperoleh dari http://jki.ui.ac.id diunduh tanggal2 Oktober 2017

Arikunto, S. (2010). Prosedur Penelitian Suatu Pendekatan Praktik. Jakarta: Rineka Cipta

Benson \& Proctor. (2011). Dasar-Dasar Respon Relaksasi: Bagaimana Menghubungkan Respon Relaksasi dengan Keyakinan Pribadi Anda (Ahli Bahasa oleh Nurhasan. Bandung: Kaifah

Benson, H \& Miriam, Z \& Klipper. (2000). Respon Relaksasi Teknik Meditasi Sederhana untuk Mengatasi Tekanan Hidup. Jakarta: Khalifah

Berman, S., \& Kozier. (2009). Buku Ajar Praktik Keperawatan Klinis Kozier. Jakarta: EGC

Datak, G., Yetti, K \& Hariyati, S.T. (2008). Penurunan Nyeri Pascabedah Pasien Turprostat melalui Relaksasi Benson. Jurnal keperawatan Indonesia, 12(3), 173178. Diperoleh dar http://jki.ui.ac.id

David T. Y. (2007). Manual Persalinan. Edisi 3. Jakarta. EGC

Departemen Kesehatan RI. (2013). Angka Penemuan Kasus Sectio Caesarea. Jakarta

Dharma, K. (2011). Metodelogi Penelitian Keperawatan. Cv Trans Info Media: Jakarta Timur

Gondo, H.K. (2011). Pendekatan Nonfarmakologis untuk Mengurangi Nyeri saat Persalinan. Jurnal CDK 185, 38(4). Diperoleh tanggal 3 Oktober 2017 dari http://kalbemed.com

Gruendemam \& Fernsebner. (2006). Buku Ajaran Keperawatan Perioperatif., Vol.2 Praktik. Jakarta: EGC

Guyton. (2010). Buku Ajar Fisiologi Kedokteran. Jakarta: EGC

Hestiantaro, A. (2009). Bayi Caesar Lebih Pintar Mitos atau Fakta. Diperoleh tanggal 3 Oktober 2017 dari http://citramedika.com

Hidayat A. (2009). Asuhan Patologi Kebidanan. Yogyakarta: Nuha Medika Hockenberry, M.J.,\& Wilson, D. (2009). Nursing Care of Infants and Children. ( $8^{\text {th }} e d$ ). St.louis: Mosby Elsevier

Kasdu. (2003). Operasi Caesar Masalah dan Solusinya. Jakarta: Puspa Swara Mansjoer, A. (2008). Kapita Selekta Kedokteran. Jakarta: Media Aesculapius Manuba \& Ida, B. G. (2007). Pengantar Kuliah Obstetric. Jakarta. EGC

Melisa. (2012). Hubungan Dukungan Sosial dengan Kualitas Hidup Pasien RSUP PROF.DR.R.D Kandaou Manado. Ejournal Keperawatan (E-KP), 1(1)

Miltenberger, R. (2004). Behaviour Modification, Principles and Procedures $3^{\text {th }}$ ed. Belmond CA: Wadsworth Thomposn Learning

Mutaqin, A. (2008). Buku Ajaran Asuhan Keperawatan Klien dengan Gangguan Rasa Nyaman terhadap Nyeri. Jakarta: Salemba Medika

Notoatmodjo, S. (2010). Metode Penelitain Keshatan. Jakarta: Rineka Cipta

Novitasari, D., \& Aryana, K.O. (2013). Pengaruh Teknik Relaksasi Benson terhadap Penurunan Tingkat Stress Lansia di Unit Rehabilitas Social Wening 
Wardoyoungaran. Jurnal keperawatan jiwa, 1(2), 186-195. Diperoleh tanggal 3 Oktober 2017 dari http://jurnal.unimus.ac.id

Nugroho, T. (2010). Kasus Emergency Kebidanan untuk Kebidanan dan Keperawatan. Yogyakarta: Nuha Medica

Nursalam. (2013). Konsep dan Penerapan Metodelogi Penelitian Ilmu Keperawatan Pedoman Skripsi, Tesis dan Instrumen Penelitian Keperawatan Edisi 2 dan 3. Jakarta: Salemba Medika

Pohan, I. (2007). Jaminan Mutu Layanan Kesehatan. Jakarta: Penerbit Buku Kedokteran EGC

Potter, \& Perry, A.G. (2005). Fundamental Keperawatan: Konsep, Proses dan Praktik, Edisi 4 Volume 1. Jakarta: Penerbit Buku Kedokteran. EGC

Potter, \& Perry, A.G. (2006). Buku Ajaran Fundamental Keperawatan: Konsep. Proses dan praktik. Vol.2 edk 4. Jakarta: EGC

Prawirohardjo, S. (2008). Ilmu Kebidanan. Jakarta: Yayasan Bina Pustakan Sarwono Prawirohardjo. Profil Kesehatan 2008

Purwanto. (2011). Pengaruh Latihan Relaksasi Religius untuk Mengurangi Insomnia di Yogyakarta. Universitas Muhammadiyah Surakarta

Ralph C, Benson. (2008). Buku Saku Obstetri dan ginekologi. Jakarta: ECG

Sanjaya, J. (2015). Terapi Benson. http://jefry-sanjayastikesmuhkusus.blogspot.co.id/2015/12/terapi-banson.html. Diakses pada 15 Oktober 2017

Sjamsuhidajat \& De Jong. (2010). Buku Ajaran Ilmu Bedah, Edisi 2. Jakarta: EGC

Smeltzer \& Bare. (2008). Texbook of Medical Surgical Nursing Vol.2. Philadelphia: Linppincot William \& Wilkins

Sujarweni, Wiratna V. (2014). Metodologi Penelitian Keperawatan. Yogyakarta: Gava Media

Syahriyani. (2010). Pengaruh Teknik Relaksasi terhadap Perubahan Intensitas Nyeri pada Pasien Post Op Apendiktomi. RSU TK II Pelamonia Makasar

Tamsuri, A. (2012). Konsep dan penatalaksanaan nyeri. Jakarta: Buku Kedokteran EGC

Taufan Nugroho, (2011). Anatomi Fisiologi Jantung dan Pembuluh Darah. Jakarta: EGC

Yosep, I. (2007). Keperawatan Jiwa. Bandung: Refika Aditama 